\title{
Numerical FEA parametric analysis of CAI behaviour of CFRP stiffened panels
}

\author{
Dimitrios G. Gaitanelis ${ }^{\mathrm{a}}$, Ioannis K. Giannopoulos ${ }^{\mathrm{a}, *}$, Efstathios E. Theotokoglou ${ }^{\mathrm{b}}$ \\ ${ }^{a}$ Centre of Excellence for Aeronautics, School of Aerospace, Transport and Manufacturing, Cranfield University, \\ Cranfield, MK43 OAL, UK \\ ${ }^{b}$ School of Applied Mathematical and Physical Sciences, Dept. of Mechanics-Lab. of Strength Materials, National \\ Technical University of Athens
}

\begin{abstract}
This paper examined the effect of numerical modelling parameters on the accuracy and computational efficiency of Carbon Fibre Reinforced Polymer (CFRP) stiffened panels under Compression After Impact (CAI). Pristine and damaged CFRP stiffened panels were subjected to compression in Abaqus ${ }^{\circledR}$ software using Cohesive Zone Model (CZM) method. Various case studies were examined and the effect of the stiffness parameters of the cohesive elements was critically assessed. Moreover, the required number of cohesive zones to fully capture the damage mechanisms of the impacted and pristine panels under compressive loading was examined. The results showed that a wrong set of parameters can even lead to neglecting the induced damage and can cause severe convergence problems in the numerical model. The importance of the Overall Meshing Factor (OMF) was highlighted and a user-defined subroutine (USDFLD) was applied to capture the decrease in the load bearing capability of an impacted panel prior to the compressive loading, since CZM was found insufficient for this scope. The above-mentioned remarks illustrated the process of investigating the optimum numerical parameters set to achieve an accurate and efficient finite element modelling of the stiffened panels structural performance and maximum load-carrying capability, when subjected to CAI loading.
\end{abstract}

Keywords: B. Delamination, C. Damage Mechanics, C. Finite Element Analysis, Cohesive Zone Model (CZM)

\section{Introduction}

Composite materials are widely applied in structural applications due to their advantageous mechanical properties. Their beneficial stiffness and strength to weight ratio has enhanced their use in the aerospace industry as well [1]. Indicatively, more than $50 \%$ per weight of the structural components in Airbus A350 and Boeing 787 are manufactured from composite materials, while the percentage in McDonnell Douglas DC-9 in the 1960s did not surpass 1\% per weight [2].

\footnotetext{
*Corresponding author

Email address: i.giannopoulos@cranfield.ac.uk (Ioannis K. Giannopoulos)
} 
In airframe structures, stiffened panels are used in components such as the wing, the fuselage and the tail. On occasions, the critical loading cases of such structures contain elements of compression which may result in buckling failure. Nonetheless, if such structures are sized properly, they can have a significant post-buckling reserve strength and the ability to carry loads that exceed considerably their initial buckling load [3]. CFRP materials, having a high specific stiffness and/or a high specific strength are ideal for stiffened panels manufacturing [4]. Due to their applicability, projects like POSICOSS (Improved Post-buckling Simulation for Design of Fibre Composite Stiffened Fuselage Structures) [5] and COCOMAT (Improved Material Exploitation at Safe Design of Composite Airframe Structures by Accurate Simulation of Collapse) [6] were funded from the European Commission in the early 00's to investigate the post-buckling and collapse behaviour of stiffened panels. Those projects focused on improving the applied numerical methods and simulation strategies for the post-buckling and collapse behaviour of the panels. Since then, there have been many advances in the computational methods and algorithms for simulating the behaviour of composite structures.

An important drawback of composite stiffened panels is the difficulty in predicting their behaviour under the presence of a structural damage. Through experimental testing, it has been found that damaged panels from impact events can have a much lower residual strength from their pristine conditioning [7]. The structural performance is highly affected by the existence of a pre and/or post-service damage, or manufacturing inherited damage [8]. Damage can occur during maintenance by dropping of tools or due to hail or runway debris, which can lead to collapse due to disbond, delamination, matrix cracking and fibre fracture [9]. The resulting damage from impact events may be difficult to observe. Provided that a foreign object high-velocity impact (HVI) can penetrate the panel, the caused damage can be easily noticed during inspection. Low-velocity impacts (LVI), on the other hand, usually cause barely visible impact damage (BVID) which could be internal to the structure in the form of delamination, not easily detected and could reduce the panel's strength even up to $60 \%$ [7].

This phenomenon has influenced the existing airworthiness regulations applied on the aircraft manufacturing industry. Aircraft structures are currently designed considering that BVID is present in the structure. Therefore, the structural elements must tolerate this damage at ultimate levels of load without failing. According to the European Aviation Safety Agency (EASA) [10] and Federal Aviation Administration (FAA) [11] Certification Specifications used in the design of aircraft, structures must prove their performance levels under in-service loading, while containing various types and sizes of damage. The acceptable means for proving structural capability according to these specifications is mainly physical testing. However, increased cost and complexity are involved in the structural testing surveys. For the reason stated above, Bisagni et al. [8] have suggested the use of a single stringer compression (SSC) specimen as an economical representative solution in investigating the post-buckling behaviour of stiffened panels. Moreover, current advances in the finite element modelling can reduce the size and scope of physical testing, especially in the early design stages. Modelling damage initiation and propagation can provide with meaningful insights to the design, hence reducing the number of articles physically tested.

Many researchers have experimentally and numerically examined the post-buckling behaviour of pristine and impacted composite stiffened panels subjected to compression [12]- [20]. Numerical investigations of CAI behaviour can capture the inter-laminar and intra-laminar damage initiation 
and propagation. For the inter-laminar damage, the Virtual Crack Closure Technique (VCCT) and the Cohesive Zone Model (CZM) are mostly applied. The main disadvantage of VCCT is the lack of damage initiation criteria [21] contrary to CZM, whose use has been recently boosted for predicting delamination growth. Despite of the method's increased application by researchers [3], [9], [14], [17], [18], [22]-[26] one of the main disadvantages of CZM is the reduced computational efficiency [9], [14], [18], [22], [23], [26]. Within the public domain literature, the need for further investigation in the modelling parameters of CZM application for increasing the accuracy and computational efficiency was evidenced. Vescovini et al. [26] and other researchers [14], [17] have managed to achieve efficient models computationally by applying a global/local approach in examining the damage initiation and propagation in composite structures. This paper aimed at contributing to the investigation of the optimum numerical recipe of CZM and a parametric analysis was conducted with several models being examined and compared aiming at faster, more robust and more accurate simulations. Through the comparison, the effect of the parameters of the cohesive properties under investigation were tested and the results were critically assessed.

The present paper is structured as follows: In the section below, the theoretical background of the implemented methods in the numerical analysis is explained. In section 3, the exact examined case study, geometry and material properties of the panel, impact experimental results and main characteristics of the numerical model are presented. In section 4, the conducted parametric studies and the followed process are analysed presenting the main results in terms of damage capture and computational efficiency. Finally, the main conclusions of the study are presented.

\section{Theoretical Background}

The two main categories of damage that are numerically modelled in laminated fibrous composite structures are intra-laminar and inter-laminar damage. Intra-laminar damage refers to the damage within a laminate (matrix cracking and fibre breakage) and inter-laminar damage is the damage caused in the interface area between laminates (debonding and delamination). To capture the intra-laminar damage in Finite Element Analysis (FEA), elements implementing the Hashin failure criterion for damage initiation were applied. This criterion, besides the allowable strength values considers the individual failure modes of the fibre and the matrix separately [27]. Damage propagation was implemented through a bilinear stiffness degradation law.

\subsection{Intra-laminar damage Initiation and Propagation - Hashin failure criterion}

In this study, the two-dimensional Hashin failure criterion was applied due to the shell property type of the element used. According to Hashin, there is an essential difference between the failure mechanics and stresses in tension and compression in the direction of fibres as well as in the transverse direction. As a result, the primary modes are examined separately for compression and tension [27]. The exact equations that were used in the numerical model for damage initiation are presented below:

1. Fibre compressive failure $\left(\hat{\sigma}_{11}<0\right)$

$$
F_{f}^{c}=\left(\frac{\hat{\sigma}_{11}}{X_{C}}\right)^{2}
$$


2. Fibre tensile failure $\left(\hat{\sigma}_{11} \geq 0\right)$

$$
F_{f}^{t}=\left(\frac{\hat{\sigma}_{11}}{X_{T}}\right)^{2}+\alpha\left(\frac{\hat{\tau}_{12}}{S_{L}}\right)^{2}
$$

3. Matrix compressive failure $\left(\hat{\sigma}_{22}<0\right)$

$$
F_{m}^{c}=\left(\frac{\hat{\sigma}_{22}}{2 S_{T}}\right)^{2}+\left[\left(\frac{Y_{C}}{2 S_{T}}\right)^{2}-1\right]\left(\frac{\hat{\sigma}_{22}}{Y_{C}}\right)+\left(\frac{\hat{\tau}_{12}}{S_{L}}\right)^{2}
$$

4. Matrix tensile failure $\left(\hat{\sigma}_{22} \geq 0\right)$

$$
F_{m}^{t}=\left(\frac{\hat{\sigma}_{22}}{Y_{T}}\right)^{2}+\left(\frac{\hat{\tau}_{12}}{S_{L}}\right)^{2}
$$

Where, $\hat{\sigma}_{11}, \hat{\sigma}_{22}, \hat{\tau}_{12}$ are components of the effective stress tensor $\hat{\sigma}$, signifying the stress along the fiber direction, the stress along the matrix direction and the intralaminar shear stress respectively. The critical strength values $X_{T}, X_{C}, Y_{T}, Y_{C}, S_{L}, S_{T}$ correspond respectively at the fibre tensile, fibre compressive, matrix tensile, matrix compressive, longitudinal and transversal shear strengths. Finally, coefficient $\alpha$, which determines the contribution of the shear stress to the fibre tensile initiation criterion, is equal to 1 in this study.

After reaching the initiation criteria, the failure modes follow a bilinear damage evolution law which is illustrated in figure 1. This constitutive relation is applied to all the failure modes to describe the material degradation by means of material stiffness reduction.

In the undamaged region, the stiffness is equal to the initial stiffness $K_{\text {init }}$. Point A is the point where the Hashin damage initiation criterion is fulfilled. After this point, material degradation begins and the stiffness (equation 5) is degraded by the damage coefficient $\mathrm{d}$ (equation 6).

$$
\begin{gathered}
K=(1-d) K_{i n i t} \\
d=\frac{\delta_{e q}^{f}\left(\delta_{e q}-\delta_{e q}^{o}\right)}{\delta_{e q}\left(\delta_{e q}^{f}-\delta_{e q}^{o}\right)}
\end{gathered}
$$

Where $\delta_{e q}^{o}$ is the initial equivalent displacement that corresponds to point $\mathrm{A}$ and $\delta_{e q}^{f}$ is the displacement when the material is completely damaged.

\subsection{Inter-laminar damage Initiation and Propagation - Cohesive zone model}

Delamination is a common inter-laminar failure mode, and according to Liu et al. [28] is favoured by mismatching bending stiffnesses between neighbouring plies that do not have the same fibre orientation. For example, in the event of a LVI being induced on a laminated fibrous composite, the small cracks between the interfaces and shear stresses can lead to delamination.

Cohesive zone modelling, which is used in numerical simulations to capture delamination, is based on constitutive models that combine strength parameters to model damage initiation and 
fracture energy parameters to model damage propagation [29]. The constitutive law of CZM employed in this study, was based on an uncoupled linear-elastic traction separation law that consists of an elastic region and a softening region (figure 2).

The peak point in figure 2 corresponds to the peak values of traction. When the critical values of normal and shear traction $N_{M A X}, S_{M A X}, T_{M A X}$ are reached, damage initiates and material degradation commences. At this point $\delta_{\text {init }}$ is the displacement where the degradation of the element begins. After this point the elements are in the softening region until $\delta_{\text {fail }}$ where the elements will assume zero stiffness. Fracture toughness $G_{C}$ is equal to the total work done until degradation. The equation that governs the traction-separation law in the softening region is the following:

$$
\mathbf{t}=\left\{\begin{array}{l}
\tau_{n} \\
\tau_{s} \\
\tau_{t}
\end{array}\right\}=\left(\begin{array}{ccc}
(1-D) K_{n n} & 0 & 0 \\
0 & (1-D) K_{s s} & 0 \\
0 & 0 & (1-D) K_{t t}
\end{array}\right)\left\{\begin{array}{l}
\delta_{n} \\
\delta_{s} \\
\delta_{t}
\end{array}\right\}=(1-D) \mathbf{K} \delta
$$

Where, $\mathbf{t}$ is the nominal traction stress vector and $\tau_{n}, \tau_{s}, \tau_{t}$ are the out-of-plane normal stress and transverse shear stresses respectively. $\mathbf{K}$ corresponds to the penalty stiffness vector and $K_{n n}$, $K_{s s}, K_{t t}$ are the normal, shear \& tearing stiffness. Moreover, $\delta$ is the relative displacement vector and $\delta_{n}, \delta_{s}, \delta_{t}$ are the normal, shear \& tearing displacements respectively. Finally, D is the damage parameter $(0 \leq \mathrm{D} \leq 1)$ and when it is equal to 0 no damage has occurred and the element is still in the elastic region. When $\mathrm{D}$ equals to 1 the element has failed.

The implemented criteria in this study for damage initiation and propagation are the quadratic nominal stress criterion and the Benzeggagh-Kenane criterion (B-K) respectively. Damage initiates when the the quadratic interaction function that involves the nominal stress ratios reaches the value of one (equation 8) and it propagates, based on fracture energy (equation 9). BenzeggaghKenane criterion is used when the critical fracture energies along the first and the second shear directions, $G_{s}^{c}$ and $G_{t}^{c}$ have the same value [30]. The governing equations of the applied criteria are the following:

- Quadratic Nominal Stress Criterion - Governing equation

$$
\left\{\frac{\left\langle\tau_{n}\right\rangle}{N_{M A X}}\right\}^{2}+\left\{\frac{\tau_{s}}{S_{M A X}}\right\}^{2}+\left\{\frac{\tau_{t}}{T_{M A X}}\right\}^{2}=1
$$

- Benzeggagh-Kenane criterion Equation (B-K) - Governing equation

$$
G_{n}^{c}+\left(G_{s}^{c}-G_{n}^{c}\right)\left\{\frac{G_{S}}{G_{T}}\right\}^{\eta}=G^{C}
$$

In equation $9, G_{S}=G_{s}^{c}+G_{t}^{c}$ and $G_{T}=G_{n}^{c}+G_{s}^{c}$. Finally, $\eta$ is a cohesive property parameter, the value of has been read from reference [31]. 


\section{Materials \& Methods}

\subsection{Panel characteristics \& impact experimental results}

In order to investigate an efficient modelling approach for CAI loading scenario, a stiffened panel with 4 I-type stiffeners was examined. The exact geometry is presented in figure 3 . The applied materials were UD carbon fiber/epoxy resin BA9916-II/HF10A-3K prepreg and plain woven BA9916-II/HFW220TA with a nominal thickness of $0.125 \mathrm{~mm}$ and $0.23 \mathrm{~mm}$ respectively. The above materials were used in the study of Feng et al. [32] where a CAI loading scenario was examined experimentally. The properties of the applied materials and the ply sequence are given in tables 1 and 2 . The symbol $*$ stands for the woven material in table 2 .

The experimental impact results of Feng et al. [32] were used. In this study, 12 composite panels were manufactured and 9 of them were impacted with $50 \mathrm{~J}$ impact energy. The panels were impacted in the mid-length of the panel in three different positions as shown in figure 3.

\subsection{Numerical Model}

The panels were modelled in Abaqus software and the effect of the impact damage on the failure initiation and propagation and overall CAI panel strength was examined. Dynamic implicit analysis was chosen as the optimal simulation scheme. The implicit analysis is unconditionally stable while the simulation is governed by the compressive displacement in terms of step sequencing, which would render an explicit scheme a more costly process due to the minimum time step required. The dynamic component in the implicit scheme aided with convergence issues encountered. Continuum shell elements were used for the skin and the stiffeners (linear hexahedral elements of SC8R type). The cohesive zones were modelled with cohesive elements COH3D8 with a finite thickness equal to $0.01 \mathrm{~mm}$ and were connected to the three-dimensional shell elements with TIE constraints. Quasi-static loading was applied with a displacement of $10 \mathrm{~mm}$. To improve convergence behaviour, viscous regularization scheme was used, with a viscosity parameter equal to $10^{-3}$ [14].

The applied boundary conditions aimed to reproduce the experimental procedure as realistically as possible [32]. For the reason stated above, the left and the right edges of the panel were constrained in the Y direction of the panel (figure 3). One end of the panel was fixed in all the three directions and the loaded end was constrained along the $\mathrm{X}$ and $\mathrm{Y}$ direction. In all the panels, a preliminary linear buckling analysis was conducted for incorporating imperfections in the form of panel shape distortions [8], [13]. Twenty eigenvalues were extracted from the analysis and an initial geometrical imperfection was applied as the $10 \%$ fraction of the first normalized eigenmode to resemble the imperfections caused by materials processing. The normalization process assigned the value of unity at the eigenmode maximum out of plane deformation. The experimental impact results of Feng et al. [32] were implemented in the numerical model by removing a rectangular cohesion zone. For positions A, B and C the dimensions of the rectangle shape were $30 \mathrm{~mm} x 15 \mathrm{~mm}$, $56 \mathrm{~mm} \times 22 \mathrm{~mm}$ and $12 \mathrm{~mm} \times 8 \mathrm{~mm}$. Finally, the values of the damage evolution in the composite material $\left(G_{I c}^{C}, G_{I c}^{T}, G_{I I c}^{C}, G_{I I c}^{T}\right)$ were the following: $G_{I c}^{C}=G_{I c}^{T}=12.5 \mathrm{~N} / \mathrm{mm}$ and $G_{I I c}^{C}=G_{I I c}^{T}=$ $1.0 \mathrm{~N} / \mathrm{mm}[3],[33]$. 


\section{Results \& Discussion}

Even though stiffened panels CAI numerical studies have been undertaken by many researchers [3], [9], [14],[17], [18], [22]-[26], the inefficient convergence behaviour of the CZM method is emphasised in many studies [9], [14], [18], [22], [24], [26]. In this paper, parametric analyses were conducted to investigate the optimum CAI modelling strategy and the effect of the critical parameters involved on the accuracy and computational efficiency.

- Effect of the parameters of the cohesive elements

The parameters that define the traction-separation law of the cohesive elements are those that influence the efficiency and the accuracy of the simulation the most. Throughout this investigation, various combinations of the properties of the cohesive elements were tested. The stiffness of the cohesive elements, the values that fulfil the nominal quadratic stress criterion and different properties for the damage evolution law were examined and the effect of these values was analysed.

- Required number of cohesive zones within the numerical model

The required number of cohesive zones that lead to an accurate simulation was questioned. In similar CAI studies, the most common method is to use cohesive elements in the interface between the skin and the stiffener as shown in figure 10 [3], [9], [17]. On the other hand, in impact studies, cohesive elements may be applied even between all the adjacent plies [34], nevertheless, the scope of these is different to the CAI simulations. To examine the optimum strategy in CAI modelling, several models were examined with increasing complexity. The simplest models had cohesive elements only between the interface area of the skin and the stiffeners. The most complex models, besides the elements in the interface area had up to 3 cohesive zones within the skin.

\section{- Effect of the Overall Meshing Factor (OMF)}

OMF is the ratio between the mesh size of the shell elements and the mesh size of the cohesive elements. In general, cohesive elements require a finer mesh to ensure the efficiency of the method [3], [9], [14], [35]. Different OMF were examined within the same model to investigate the importance of this particular parameter in the final results.

- Load - bearing capability of the pristine and impacted panels

The method for numerically implementing pre-existing material degradation caused by the impact, apart from layer decohesion, was investigated.

\subsection{Eigenvalue/eigenmode analysis}

To examine the post-buckling behaviour of the stiffened panel under compression, it is a good design practice, prior to establishing the non-linear finite element model with progressive damage, to understand the way the stiffened panel is expected to behave deformation-wise in the postbuckling region, meaning the buckling mode shapes. For that purpose, a linear eigenvalue/eigenmode 
study can reveal the deformation pattern the panel would ideally like to assume in the post-buckling region under compression.

In the existing literature, various researchers have addressed the effect of the initial imperfections on the post-buckling behaviour of a composite structure and have produced optimisation tools that consider this effect on the design process. An interesting study of Barbero et al. [36] introduced a novel methodology for the analysis of slender elastic structures using Koiter's asymptotic approach accompanied with the Monte Carlo method. With this method, the researchers performed an imperfection sensitivity analysis and within a few seconds managed to detect the worst imperfection considering a large number of modes and the various possible interactions between them. With this tool, they were able to evaluate statistically the effect of the imperfection on the load capacity as well as the sensitivity to the amplitude of the worst imperfection. With a similar strategy based on stochastic simulations, Liguori et al. [37], produced a tool to optimise the stacking sequence of slender composite shells detecting both the best layup and the worst shape of geometrical imperfection and its effect on the collapse load. Moreover, in their most recent work, Liguori et al. [38] applied this Koiter-inspired method, coupled with Monte-Carlo and stochastic algorithm, to optimise the post-buckling behaviour of a variable angle tow (VAT) wingbox. As a matter of fact, they achieved more than $80 \%$ reduction in the out-of-lane displacement in the post-buckling regime of the examined structure.

In this study, a simpler approach is followed to examine the criticality of the location and the size of the induced damage on the post-buckling behaviour of the stiffened panels.

The first eigenmode can resemble the initial buckling deformation pattern on cases where there is no buckling mode interaction in the vicinity of the first eigenvalue. The locations of tension/compression/shear based on the eigenmode shape, will indicate the location which will more severely affect the panel structural performance. For example, in the modelled cohesive zone, modelling a pre-existing damage in the areas under tension will be more detrimental to the overall panel strength. The panel design in terms of symmetric or un-symmetric stiffeners, the torsional stiffness of the stiffener-panel skin assembly, the stiffness ratio between the panel bays and stiffeners, will sketch out the locations on the panel of severe tension and/or shear. The effect of existing damage on the stiffened panel can affect the linear eigenvalue/eigenmode solution, mainly depending on their relative size in relation to the panel as well as the panel's design parameters. In short, the eigenvalue solution can readily provide with some insights to whether the location and the size of an introduced damage is critical for the damage to propagate from the implanted damage location in the impacted case-study compared to the pristine case. For instance, the areas under critical loading may have been shifted in location or altered altogether due to the pattern of the assumed buckled shape being affected by the implanted damage (figure 4).

In figure 4, the effect of the size of the de-cohered area on the eigenvalue/eigenmode is shown. Depending on the size of the damage mainly but also on the panel design/stiffness parameters, the structural performance of the panel will be more severely affected. Bisagni et al. [8] applied initial imperfections in their models associated with an eigenvalue analysis and observed that minor imperfections can influence the post-buckling mode and can also affect the initiation and propagation of the skin/stringer delamination. In this study, in position $\mathrm{C}$, the size of the induced damage did not affect the eigenvalue/eigenmode analysis contrary to position $\mathrm{B}$, which shows that the implemented damage in this location is not that critical. 
As mentioned above, it is a good design strategy to examine the eigenmode shapes of the undamaged panel for tracking the locations where implanting a damage will more severely affect the panel structural performance. Also, examining the eigenmode shapes of a panel with an induced damage, for enquiring the damage effect on the buckling shapes compared to the pristine case, will provide some insight on the criticality of the size of the induced damage.

In all, these studies can be useful to assess the most critical set of impacted cases considering the number, relative sizes and damage implantation location on the panels with a low computational cost. It is the author's opinion that more holistic tools [36], [37], [38] could be implemented for achieving the optimum structure considering the initial imperfection. However, this is beyond the scope of this study and a simpler eigenvalue/eigenmode analysis is applied to obtain an insight on the criticality of the induced damage on the post-buckling behaviour of the examined panels.

\subsection{Effect of the parameters of the cohesive elements}

Impacted panel in position $\mathrm{C}$ was examined (figure 3) and several models were tested with different properties of the cohesive elements. In table 3 the properties of the initial four examined cases are presented. The applied values were derived from specific studies of other researchers and in those models the same values for the damage evolution were applied.

It was found that the properties of the cohesive elements can even sideline the induced delamination located to the mid-length of the panel in the numerical model. The results shown in figure 5, indicated that the properties of the cohesive elements were responsible for the initial buckling shape deviation, hence the different location in the matrix damage initiation and subsequent propagation, but not on the overall failure load. Model 1 had the optimum convergence behaviour, models 1 and 2 were further examined in order to improve the accuracy of model 1 and the computational behaviour of model 2. Models 5, $6 \& 7$ are variations of model 1 and model 8 is a variation of model 2.

In model 1, even though the damage initiated from the impact point, the damage propagation was stable after a specific point of the simulation. Three versions of model 1 were examined with the same elastic properties. Damage initiation criteria of models 2 and 3 (table 3 ) were implemented in the first two new versions and in the third model different properties for the damage evolution were applied [3]. A version of model 2 with those damage evolution properties [3] was examined as well to improve its convergence behaviour. The exact properties of the four new models are presented in table 4.

Elements that fulfil the quadratic nominal stress criterion are presented to illustrate the model's damage behaviour. In figures 6 and 7, the cohesive element with the induced damage in the interface area of the skin and the stiffener is presented for the examined models. The red colour corresponds to the elements that have reached the peak values and when an element reaches $99 \%$ of its initial stiffness, element deletion is applied. In figure 6, it is observed that in models 5 and 6 damage initiates from the impact point but does not propagate. The same behaviour was noticed in model 1 of table 3. Hence, applying different damage initiation values did not affect the accuracy of the simulation.

In model 7, with a different set of damage evolution parameters, damage initiated from the impact point and propagated throughout the entire simulation, contrary to models 5 and 6 . However,the damage propagated with a higher rate on the quarter length of the panel comparing to the 
impacted region (figure 7). This does not necessarily lead to the conclusion that the model is inaccurate. From the experimental impact results in position $\mathrm{C}$, the measured crater depth and damage area were even equal to 0 for one of the tests. Hence, impacting position $\mathrm{C}$ for the experimental study did not affect the panel essentially. In all, an induced delamination of $12 \mathrm{~mm} \times 8 \mathrm{~mm}$ in position $\mathrm{C}$ in the numerical model might not suggest a severe enough damage scenario to drive the damage initiation and global failure propagation of the panel.

Models with higher elastic properties had a different behaviour. It was observed that by increasing the elastic properties, damage propagated more globally within the model. In model 8 , damage initiated from the impact point but the peak vales were reached in various regions within the model, where element deletion took place as well (figure 8).

Both of the models in figures 7 and 8 provide meaningful predictions for the damage initiation and propagation. In the first model, the induced delamination does not define the damage mechanics of the panel while in model 8 the damage propagated more globally. In our study, the implanted delamination damage was at a different location than the ones indicated as critical by the eigenvalue/eigenmode study (figure 4). That served the purpose of monitoring the superimposed effect and the bridging of defects between the implanted damage and the delamination emanating from the critical location. The size of the damage was found to be an important parameter as experienced in the numerical models B, C. The existing delamination in position B $(56 \mathrm{~mm} \times 22 \mathrm{~mm})$ had a much more important effect than the damage size in position $\mathrm{C}(12 \mathrm{~mm} \times 8 \mathrm{~mm})$ shown in figure 3 , since it compromised the panel structural integrity at the stiffener location.

Considering the computational efficiency of the simulations, it was observed that increasing the elastic parameters of the cohesive elements, the models become computationally inefficient. In table 5, the examined models of table 3 are presented. All of those models followed the same damage evolution law parameters and had increasing elastic properties.

In the examined models, each time step increment corresponded to ten increments in the requested field output. It was evident, that as the cohesive elements get stiffer, the convergence issues increased. For instance, model 4 with the highest elastic parameters achieved $0.24 \%$ increase in 2200 increments. On the other hand, model 1 had already surpassed 52.5\% of the total simulation step at time increment 1050. In order to strengthen this conclusion the quadratic nominal stress criteria of models $3 \& 4$ are presented in figure 9.

Comparing the quadratic nominal stress criterion plots for the presented models, it was noticed that by increasing the elastic parameters of the cohesive elements, the number of elements that reached the critical values increased (red colour in figures 6 -9). By increasing the elastic parameters, the majority of the elements of the cohesive zones reached the critical values of degradation simultaneously which lead to non convergent models (figure 2). On the other hand, models with smaller elastic properties degraded in local regions. As a result, a smaller number of elements reaches the critical values for damage initiation and the computational behaviour is improved (figures 6 - 7).

\subsection{Required number of cohesive zones within the numerical model}

In order to produce the optimum CAI model the number of cohesive zones within the model was assessed. For this case-study impacted model A was examined. This panel is impacted in the 
unstiffened region, in the middle skin bay of the panel. Schematic figures of the examined models are presented below (figure 10).

Two different models were examined. Model A-1 with one cohesive zone within the skin and model A-2 with three cohesive zones within the skin and cohesive elements in the interface area between the skin and the stiffeners. The cohesive zones within the skin were located between adjacent plies with different fibre orientations in the two models. The scope of this study was to examine the required complexity of a model in order to capture the propagated damage.

As it was expected, the more complex model A- 2 captured the damage mechanics in a greater detail. However, the computational efficiency was reduced. From figure 11, it is clear that in order to capture more accurately the stiffener's breakage in a model, cohesive elements must be implemented in the interface area of the skin and the stiffeners. The damage in the middle stiffeners in model A-1 that had no interface elements was not fully captured. Hence, interface elements are necessary in this area. As far as the cohesive elements within the skin are concerned, the results showed that, for model A-2 the greatest damage was captured in the cohesive zone within the top plies of the skin.

From figure 12, it can be seen that the cohesive elements in the middle and bottom plies had no elements that reached the critical values for damage initiation (red colour). Applying cohesive elements in this particular areas was redundant and the computational cost was greater than the increase in accuracy. To sum up, the optimum strategy to model CAI behaviour when the damage is induced in the unstiffened area of the skin is to apply one cohesive zone within the top plies of the skin and cohesive elements in the interface area of the skin and the stiffeners.

\subsection{Effect of the overall meshing factor $(O M F)$}

The final analysis took place to examine the effect of the OMF in the accuracy of the CZM method. It was found that an OMF equal to 4 produced accurate results and that ratio was used in the models. A greater refinement produced an increased computational cost rather than achieving a greater accuracy. One of the impacted models in position $\mathrm{C}$ is presented to illustrate the effect of the OMF on the damage capture in the numerical model (figure 13).

Within the same model, cohesive zones with different overall meshing factors were implemented. The parameters of the cohesive zones were derived from the sensitivity analysis of section 4.2. In all the cohesive zones the parameters of model 7 of table 4 were used. For an OMF equal to 4 the damage initiated and propagated as in figure 7. For the cohesive zones within the skin, in the top plies with an OMF equal to 2 the method produced results but the damage did not initiate from the impacted point (figure 14). For an OMF less than 2 the method was unsuccessful (figure $15)$.

As a result, it is clear that cohesive elements require a denser mesh compared to the mesh of the shell elements for the CZM method to function properly. In this study, as in the study of Akterskaia et al. [14], an OMF equal to four produced the optimum results while a greater refinement increased the computational cost. On the other hand, a reduced refinement lead to neglecting the induced damage in the examined models. 


\subsection{Load-bearing capability of the pristine and impacted panels}

For impact energies up to $50 \mathrm{~J}$ and for stiffened panel geometries similar to the ones modelled, modelling impact damage as a de-cohered area is not sufficient to capture the decrease in the load bearing capability of an impacted panel prior to the compressive loading. As it can be seen in figure 16 the impacted and pristine panel reached a failure load close to $1016 \mathrm{kN}$. The similar failure loads showed that the load-bearing capability of the examined panels was not affected by the induced delamination.

To achieve an accurate CAI model, a user-defined subroutine (designated as USDFLD in Abaqus) was applied to consider the material degradation in the impacted region apart from the de-cohered area. A material damage degradation coefficient d equal to 0.1 and 0.4 along the fibre direction was used in the shell elements of the skin and the bottom flange of the stiffener in the impacted area, same in size and location as the modelled de-cohered area. The force - displacement diagrams for the impacted panel in position B with and without the material degradation are presented in figure 17.

When $\mathrm{d}=1$ and the impacted region has not been degraded, the failure load is equal to the pristine panel's $(1016 \mathrm{kN})$. On the other hand, when $\mathrm{d}=0.4$ the failure load is $979 \mathrm{kN}$ and when $\mathrm{d}=0.1$ the failure load is $915 \mathrm{kN}$, achieving a 3.6\% and 10\% reduction in the load bearing capability respectively. This latter assumption in the damage coefficient produced numerical results that correctly captured the $10 \%$ in the CAI strength decrease of the impacted panel in position B, where the average failure load was reduced from $956 \mathrm{kN}$ (pristine) to $861.3 \mathrm{kN}$ (10\% decrease) [32].

\section{Conclusions}

The conducted investigation exposed in this paper, presented a parametric analysis which resulted in suggested optimum modelling methodology and parameters for simulating CAI behaviour of damaged composite stiffened panels utilising current commercial packages, Abaqus ${ }^{\circledR}$ in this case. Existing experimental results were cross-referenced [32] and the numerical models were assessed in accuracy and computational efficiency. The resulting CAI strength reduction from the numerical models correlated well with the experimental results of Feng et al. [32]. More precisely, similar structural performance trends were seen and the percentage in the reduction of the pristine stiffened panel's strength was verified. From this process, some interesting observations were made, aimed at raising the awareness and summarizing the importance of the major parameters affecting the simulation and structural performance prediction results of CFRP stiffened panels. Finally, an interaction between the damage size and location implanted with the modes of buckling was observed. The main conclusions are presented below.

- Effect of the cohesive properties

It was found that a wrong combination of CZM properties can even lead to neglecting the presence of an existing delamination within the model. Also, higher elastic parameters of the cohesive elements lead to convergence issues. Stiffer cohesive elements tend to distribute the damage globally rather than in local areas. As a result, the majority of the elements reaches the critical values 
for material degradation simultaneously. This parallel material degradation of the elements (due to the traction-separation law) leads to inefficient computational behaviour. Material modelling parameters are very sensitive and only experimental results can be used for model verification. Correlation with the experimental results is necessary to ensure the accuracy with the numerical model.

- Effect of the number of the cohesive zones within the numerical model

Modelling the interface area of the skin and the stiffeners with cohesive elements is required to capture accurately failure modes such as the stiffener's breakage. Moreover, the maximum delamination propagation was captured in the cohesive zone located within the top plies of the skin. The middle and bottom cohesive areas had a reduced effect and can be considered redundant. In all, increasing the number of cohesive areas within the model increases the accuracy; however, this particular benefit does not offset the computational disadvantages.

\section{- Effect of the OMF}

Properties of the cohesive elements are strongly dependent on the OMF and should be varied according to the applied mesh ratio. In this study, after a sensitivity analysis, an OMF equal to four produced accurate results with a reduced computational cost.

- Load-bearing Capability

CZM method does not capture fully the material degradation caused by an impact. For the reason stated above, tools like the user-defined subroutine USDFLD was implemented in the model to capture the decrease in the load-bearing capability caused by the impact. Damage degradation coefficients 0.4 and 0.1 lead to a $3.6 \%$ and $10 \%$ reduction in the load bearing capability respectively.

Funding: This study did not receive any specific financial support for the conduct of the research and preparation of the article.

\section{References}

[1] Stroud WJ, Greene WH, Anderson MS. Buckling loads of stiffened panels subjected to combined longitudinal compression and shear: results obtained with PASCO, EAL, and STAGS computer programs. NASA Langley Research Center 1984;NASA-TP-2215,NAS 1.60:2215,L-15630.

[2] Dillingham GL. Aviation Safety: Status of FAA's Actions to Oversee the Safety of Composite Airplanes. United States Government Accountability Office 2011;GAO-11-849:1-20.

[3] Wang XM, Cao W, Deng CH, Wang PY, Yue ZF. Experimental and numerical analysis for the postbuckling behavior of stiffened composite panels with impact damage. Compos Struct 2015;133:840-846. doi:10.1016/j.compstruct.2015.08.019.

[4] Abramovich H, Weller T. Buckling and postbuckling behavior of laminated composite stringer stiffened curved panels under axial compression: Experiments and design guidelines, J Mech Mater Struct 2009;4(78):1187-1207. doi:10.2140/jomms.2009.4.1187. 
[5] Zimmermann R, Rolfes R. POSICOSS - Improved postbuckling simulation for design of fibre composite stiffened fuselage structures, Compos Struct 2006;73(2):171-174. doi:10.1016/j.compstruct.2005.11.041.

[6] Degenhardt R, Rolfes R, Zimmermann R, Rohwer K. COCOMAT - Improved material exploitation of composite airframe structures by accurate simulation of postbuckling and collapse, Compos Struct 2006;73(2):175-178. doi:10.1016/j.compstruct.2005.11.042.

[7] Rhead AT, Marchant D, Butler R. Compressive strength of composite laminates following free edge impact, Compos Part A Appl Sci Manuf 2010;41(9):1056-1065. doi:10.1016/j.compositesa 2009.10.024

[8] Bisagni C, Dávila C.G. Experimental investigation of the postbuckling response and collapse of a single stringer specimen, Composite Structures 2014; 108: 493-503. https://doi.org/10.1016/j.compstruct.2013.09.018

[9] Masood S. N, Vishakh R, Viswamurthy SR, Gaddikeri KM, Sridhar I. Influence of stiffener configuration on post-buckled response of composite panels with impact damages, Compos Struct 2018;194:433-444. doi:10.1016/j.compstruct.2018.04.005

[10] EASA. Certification Specifications and Acceptable Means of Compliance for Large Aeroplanes;CS25.

[11] FAA. 14 CFR Part 23 - Airworthiness Standards: Normal Category Airlanes, Subpart C, Structures.

[12] Volkan K. Buckling analysis of laminated composite and sandwich beams by the finite element method, Compos Part B Eng 2016;91:126-134. doi:10.1016/j.compositesb.2016.01.031

[13] Boni L, Fanteria D, Lanciotti A. Post-buckling behaviour of flat stiffened composite panels: Experiments vs analysis, Compos Struct 2012;94(12):3421-3433. doi:10.1016/j.compstruct.2012.06.005

[14] Akterskaia M, Jansen E, Hallett SR, Weaver P, Rolfes R. Analysis of skin-stringer debonding in composite panels through a two-way global-local method, Compos Struct 2018;202:1280-1294. doi:10.1016/j.compstruct.2018.06.064

[15] Tserpes KI, Karachalios V, Giannopoulos I, Prentzias V, Ruzek R. Strain and damage monitoring in CFRP fuselage panels using fiber Bragg grating sensors. Part I: Design, manufacturing and impact testing, Compos Struct 2014;107:726-736. doi:10.1016/j.compstruct.2013.09.053

[16] Ruzek R, Kudrna P, Kadlec M, Karachalios V, Tserpes KI. Strain and damage monitoring in CFRP fuselage panels using fiber Bragg grating sensors. Part II: Mechanical testing and validation, Compos Struct 2014;107:737-744. doi:10.1016/j.compstruct.2013.09.056

[17] Riccio A, Sellitto A, Saputo S, Russo A, Zarrelli M, Lopresto V. Modelling the damage evolution in notched omega stiffened composite panels under compression. Compos Part B Eng 2017;126:60-71. doi:10.1016/j.compositesb.2017.05.067

[18] Tan KT, Watanabe N, Iwahori Y. Finite element model for compression after impact behaviour of stitched composites, Compos Part B Eng 2015;79:53-60. doi:10.1016/j.compositesb.2015.04.022.

[19] Ouyang R, Sun W, Guan Z, Tan R, Li Z. Experimental study on delamination growth of stiffened composite panels in compression after impact, Compos Struct 2018;206:791-800. doi:10.1016/j.compstruct.2018.08.080.

[20] Orifici AC, Alberdi I, Thomson RS, Bayandor J. Compression and post-buckling damage growth and collapse analysis of flat composite stiffened panels, Compos Sci Technol 2008;68(15-16):3150-3160. doi:10.1016/j.compscitech.2008.07.017.

[21] Curiel Soza JL. Finite Element Analysis of Progressive Degradation versus Failure Stress Criteria on Composite Damage Mechanics. In: Advances in Composite Materials - Ecodesign and Analysis. INTECH, ISBN: 978-953307-150-3, 2011. doi: 10.5772/13886.

[22] Turon A, Dávila C.G, Camanho PP, Costa J. An engineering solution for mesh size effects in the simulation of delamination using cohesive zone models, Eng Fract Mech 2007;74(10):1665-1682. doi:10.1016/j.engfracmech.2006.08.025.

[23] Cao D, Duan Q, Hu H, Zhong Y, Li S. Computational investigation of both intra-laminar matrix cracking and inter-laminar delamination of curved composite components with cohesive elements, Compos Struct 2018;192:300-309. doi:10.1016/j.compstruct.2018.02.072.

[24] Shor O, Vaziri R. Application of the local cohesive zone method to numerical simulation of composite structures under impact loading, I.J Imp Eng 2017;104:127-149. doi:10.1016/j.ijimpeng.2017.01.022.

[25] Truong VH, Nguyen KH, Park SS, Kweon JH. Failure load analysis of C shaped composite beams using a cohesive zone model, Compos Struct 2018;184:581-590. doi:10.1016/j.compstruct.2017.10.035.

[26] Vescovini R, Dávila C.G, Bisagni C. Failure analysis of composite multi-stringer panels using simplified models, 
Composites Part B: Engineering 2013; 45: 939-951. https://doi.org/10.1016/j.compositesb.2012.07.030

[27] Hashin Z. Failure criteria for unidirectional fibre composites, J Appl Mech 1980;47(2):329-334. doi:10.1115/1.3153664.

[28] Liu D. Impact-Induced Delamination - A View of Bending Stiffness Mismatching, J Compos Mater 1988; 22(7):674-692. doi:10.1177/002199838802200706

[29] Maimí P, Camanho PP, Mayugo JA, Dávila C.G. A continuum damage model for composite laminates: Part I Constitutive model, Mech of Mater 2007;39(10):897-908. doi:10.1016/j.mechmat.2007.03.005.

[30] Benzeggagh ML, Kenane M. Measurement of mixed-mode delamination fracture toughness of unidirectional glass/epoxy composites with mixed-mode bending apparatus, Compos Sci Technol 1996;56(4):439-449. doi:10.1016/0266-3538(96)00005-X.

[31] Dassault Systemes Simulia Corp., Abaqus 6.11, User's Manual; 2011.

[32] Feng Y, Zhang H, Tan X, He Y, An T, Zheng J. Effect of impact damage positions on the buckling and post-buckling behaviors of stiffened composite panel, Compos Struct 2016;155:184-196. doi:10.1016/j.compstruct.2016.08.012.

[33] Ge D, Mo Y, He B, Wu Y, Du X. Experimental and numerical investigation of stiffened composite curved panel under shear and in-plane bending, Compos Struct 2016;137:185-195. doi:10.1016/j.compstruct.2015.09.049.

[34] Zhang J, Zhang X. An efficient approach for predicting low-velocity impact force and damage in composite laminates, Compos Struct 2015;130:85-94. doi:10.1016/j.compstruct.2015.04.023.

[35] Hallett SR, Harper PW. Modelling delamination with cohesive interface elements. In: Numerical Modelling of Failure in Advanced Composite Materials, 2015;55-72. ISBN: 9780081003329, doi: 10.1016/B978-0-08100332-9.00002-5.

[36] Barbero E.J, Madeo A, Zagari G, Zinno R, Zucco G. Imperfection sensitivity analysis of laminated folded plates, Thin-Walled Structures 2015; 90: 128-139. https://doi.org/10.1016/j.tws.2015.01.017

[37] Liguori F.S, Madeo A, Magisano D, Leonetti L, Garcea G. Post-buckling optimisation strategy of imperfection sensitive composite shells using Koiter method and Monte Carlo simulation, Composite Structures 2018; 192 : 654-670. https://doi.org/10.1016/j.compstruct.2018.03.023

[38] Liguori F.S, Zucco G, Madeo A, Magisano D, Leonetti L, Garcea G, Weaver P.M. Postbuckling optimisation of a variable angle tow composite wingbox using a multi-modal Koiter approach, Thin-Walled Structures 2019; 138: 183-198. https://doi.org/10.1016/j.tws.2019.01.035

[39] Masood SN, Viswamurthy SR, Muthukumar M, Kumar SA, Kotresh GM. Simulation and validation of disbond growth in co-cured composite skin-stringer specimens using cohesive elements, J Compos mater 2017;52(6):807822. doi:10.1177/0021998317715505. 


\section{Figure Captions}

- Figure 1: Intra-laminar damage initiation and propagation - Schematic Figure

- Figure 2: Traction-Separation law - Schematic figure

- Figure 3: Panel Geometry \& impact positions A,B \& C

- Figure 4: First eigenvalue/eigenmode of the pristine and impacted panels B \& C

- Figure 5: Matrix compression damage in the models of table 3

- Figure 6: Quadratic nominal stress criterion in models 5 \& 6

- Figure 7: Quadratic nominal stress criterion in model 7

- Figure 8: Quadratic nominal stress criterion in model 8 for four indicative applied displacements

- Figure 9: Quadratic nominal stress criterion in model 3 and 4

- Figure 10: Schematic figure of examined impacted models in position A

- Figure 11: Tensile matrix damage in models A-1 \& A-2

- Figure 12: Quadratic nominal stress criterion within the skin in model A-2

- Figure 13: Schematic figure of the OMF model

- Figure 14: Quadratic nominal stress criterion with an OMF equal to 2

- Figure 15: Quadratic nominal stress criterion with an OMF less than 2

- Figure 16: Force - Displacement diagrams for the pristine \& impacted panels

- Figure 17: Force - Displacement diagrams for position B with damage degradation coefficient equal to $0.1,0.4 \& 1$ 
Table 1: Material properties of UD BA9916-II/HF10A-3K and plain woven BA9916-II/HFW220TA

\begin{tabular}{cccccccc}
\hline \multicolumn{7}{c}{ UD BA9916-II/HF10A-3K } \\
\hline$E_{11} / M P a$ & 124.000 & $E_{22} / M P a$ & 10.000 & $E_{33} / M P a$ & 10.000 & $G_{12} / M P a$ & 4510 \\
$G_{13} / M P a$ & 45100 & $G_{23} / M P a$ & 3260 & $v_{12}$ & 0.16 & $v_{13}$ & 0.16 \\
$v_{23}$ & 0.2 & $X_{t} / M P a$ & 1448 & $Y_{t} / M P a$ & 55 & $X_{c} / M P a$ & 1172 \\
$Y_{c} / M P a$ & 172 & $S_{12} / M P a$ & 90 & $S_{13} / M P a$ & 161 & $S_{23} / M P a$ & 161 \\
\multicolumn{7}{c}{ Plain Woven BA9916-II/HFW220TA } \\
$E_{11} / M P a$ & 55.000 & $E_{22} / M P a$ & 52.000 & $E_{33} / M P a$ & 56.000 & $G_{12} / M P a$ & 4140 \\
$G_{13} / M P a$ & 4140 & $G_{23} / M P a$ & 3760 & $v_{12}$ & 0.28 & $v_{13}$ & 0.28 \\
$v_{23}$ & 0.30 & $X_{t} / M P a$ & 600 & $Y_{t} / M P a$ & 540 & $X_{c} / M P a$ & 631 \\
$Y_{c} / M P a$ & 584 & $S_{12} / M P a$ & 60 & $S_{13} / M P a$ & 60 & $S_{23} / M P a$ & 116
\end{tabular}


Table 2: Ply sequence and thickness of the examined skin \& stiffener

\begin{tabular}{cccc}
\hline & Ply sequence & Total No. of plies & Total thickness $(\mathrm{mm})$ \\
\hline Skin & {$\left[45^{*} / 45 / 0 / 0 / 0 /-45 / 90 / 0 / 90\right]_{s}$} & 18 & 2.46 \\
Stiffener & {$[-45 / 0 / 0 / 45 / 0 / 0 /-45 / 0 / 0 / 45 / 90]_{s}$} & 22 & 2.75
\end{tabular}


Table 3: Examined properties

\begin{tabular}{ccccc}
\hline Parameters & $\begin{array}{c}K_{N N} \\
\left(N / m^{3}\right)\end{array}$ & $\begin{array}{c}K_{S S}=K_{T T} \\
\left(N / m^{3}\right)\end{array}$ & $\begin{array}{c}N_{M A X} \\
\left(N / m^{2}\right)\end{array}$ & $\begin{array}{c}S_{M A X}=T_{M A X} \\
\left(N / m m^{2}\right)\end{array}$ \\
\hline Model 1, [39] & 3,250 & 24,920 & 54 & 80 \\
Model 2, [34] & 240,000 & 86,000 & 64 & 121 \\
Model 3, [17] & $1,000,000$ & $1,000,000$ & 60 & 90 \\
Model 4, [3] & $1,150,000$ & 600,000 & 54 & 80 \\
\hline
\end{tabular}

$G_{I c}=0.325 \mathrm{~N} / \mathrm{mm}, \quad G_{I I c}=G_{I I I c}=2.492 \mathrm{~N} / \mathrm{mm}, \quad \eta=2.193$ 
Table 4: Properties of the new examined models

\begin{tabular}{cccccccc}
\hline \multirow{2}{*}{ Models } & \multicolumn{2}{c}{ Elastic Parameters } & \multicolumn{2}{c}{ Damage Initiation } & \multicolumn{3}{c}{ Damage evolution } \\
& $K_{N N}$ & $K_{S S}=K_{T T}$ & $N_{M A X}$ & $S_{M A X}=T_{M A X}$ & $G_{I c}$ & $G_{I I c}=G_{I I I c}$ & $\eta$ \\
$\left(N / m^{3}\right)$ & $\left(N / m^{3}\right)$ & $\left(N / m^{2}\right)$ & $\left(N / m^{2}\right)$ & $(N / m m)$ & $(N / m m)$ & \\
\hline Model 5 & 3,250 & 24,920 & 60 & 90 & 0.325 & 2.492 & 2.193 \\
Model 6 & 3,250 & 24,920 & 64 & 121 & 0.325 & 2.492 & 2.193 \\
Model 7 & 3,250 & 24,920 & 54 & 80 & 0.243 & 0.514 & 4.6 \\
Model 8 & 240,000 & 86,000 & 64 & 121 & 0.243 & 0.514 & 4.6
\end{tabular}


Table 5: Convergence behaviour of the 4 initially examined models

\begin{tabular}{ccccc}
\hline Parameters & Model 5 & Model 8 & Model 3 & Model 4 \\
\hline$K_{N N}$ & 3,250 & 240,000 & $1,000,000$ & $1,150,000$ \\
$K_{S S}, K_{T T}$ & 24,920 & 86,000 & $1,000,000$ & 600,000 \\
Increment & 2450 & 1140 & 1430 & 1270 \\
Time step & 0.6802 & 0.4737 & 0.4563 & 0.4555 \\
Increment 1050 & 0.5256 & 0.4677 & 0.4518 & 0.4531
\end{tabular}




\section{Equivalent Stress}

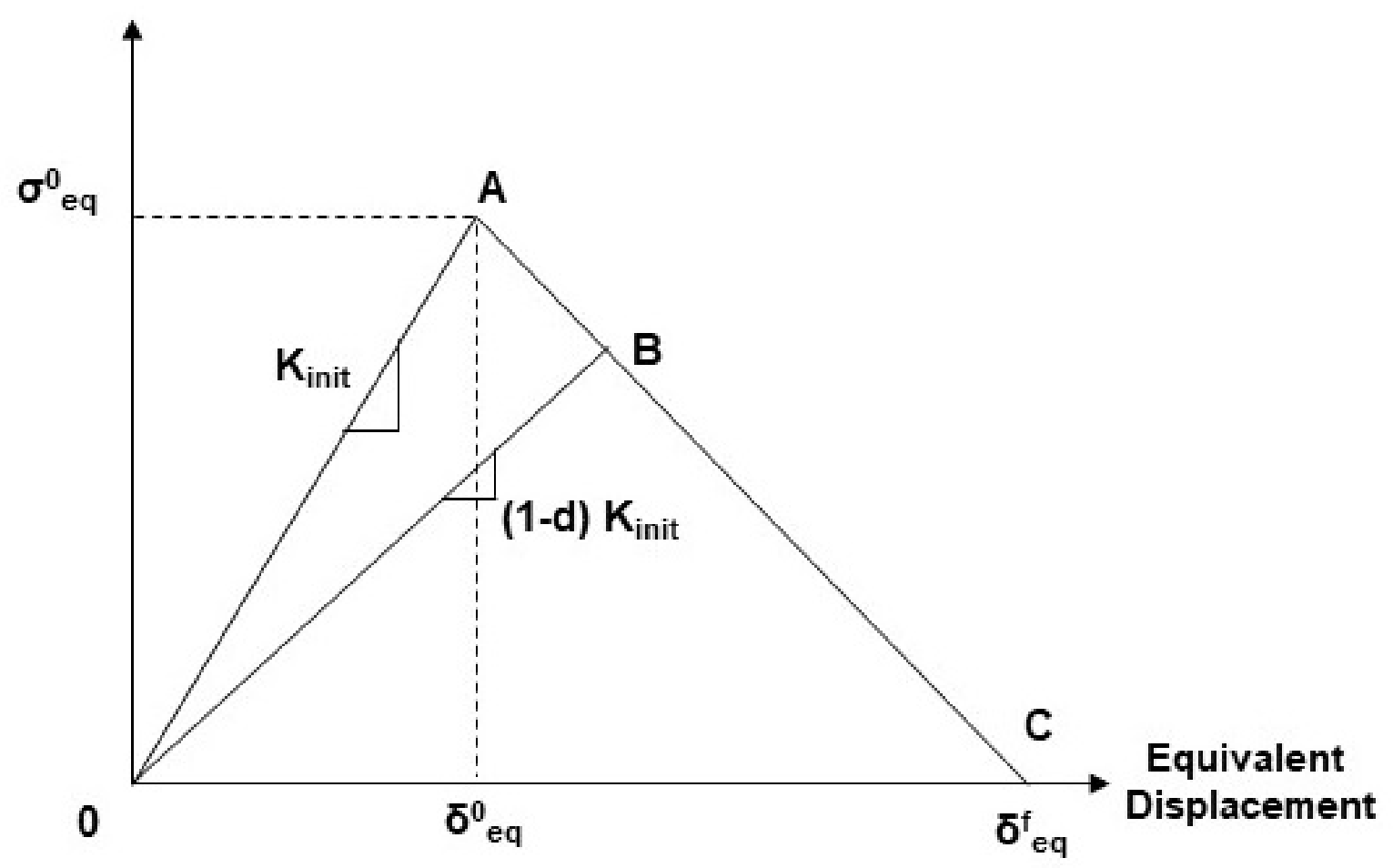

Figure 1: Intra-laminar damage initiation and propagation - Schematic Figure 


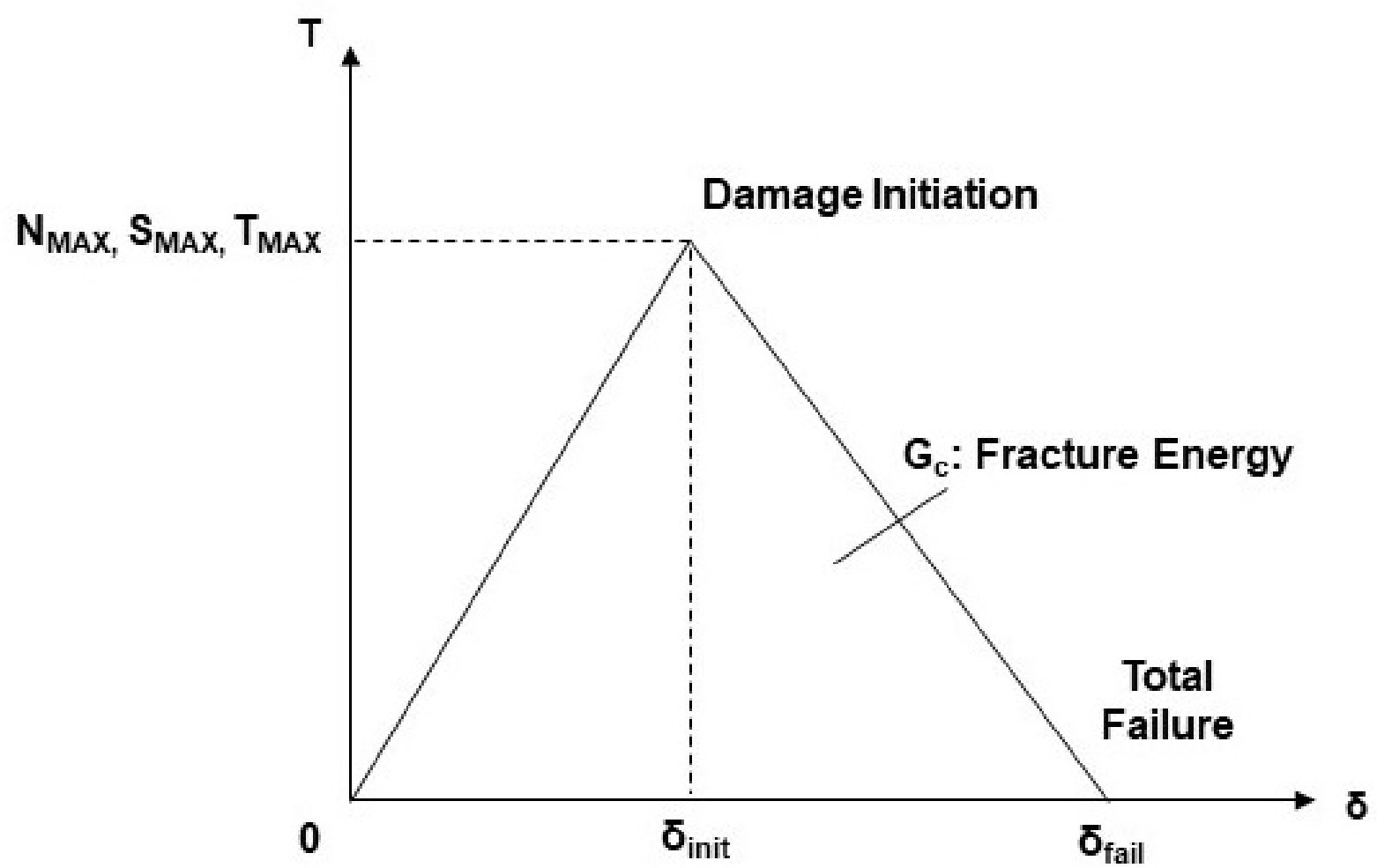

Figure 2: Traction-Separation law - Schematic figure 


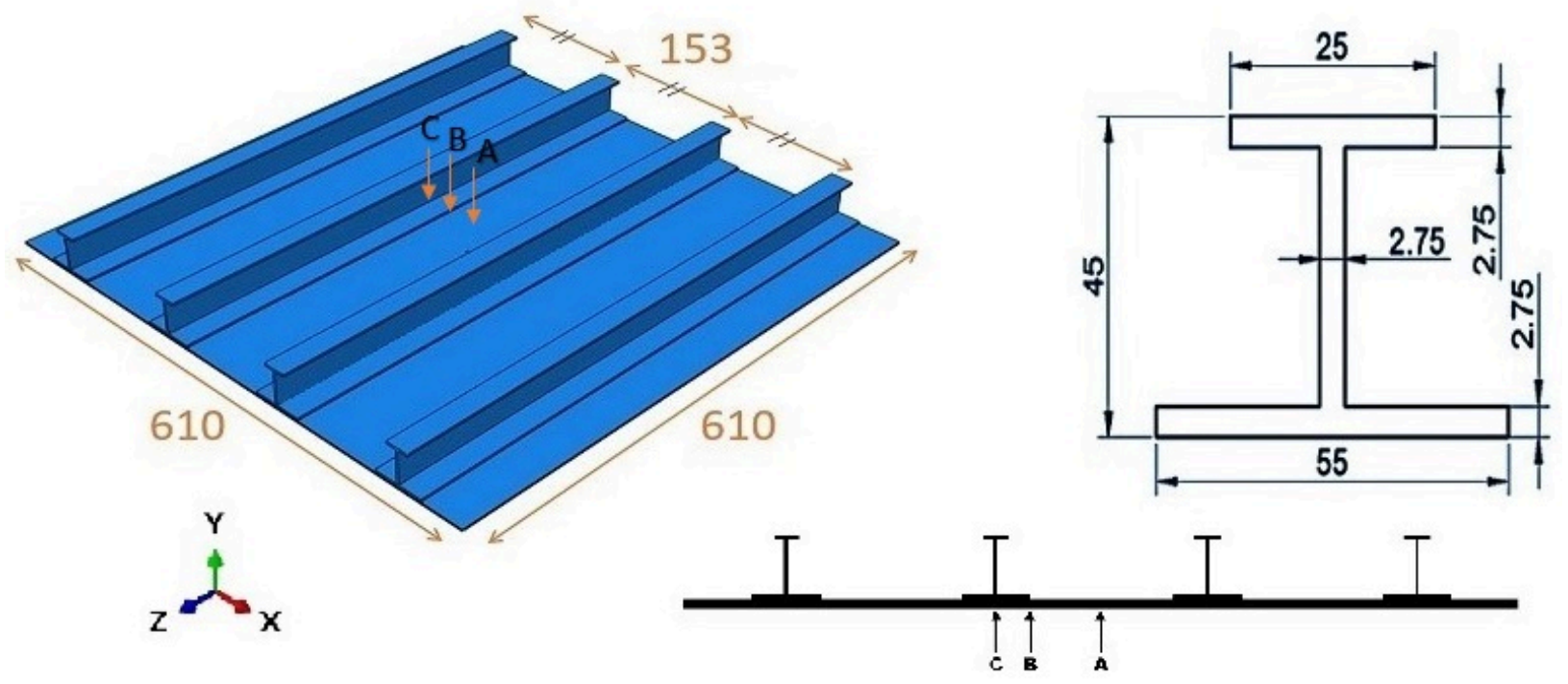

Figure 3: Panel Geometry \& impact positions A,B \& C 


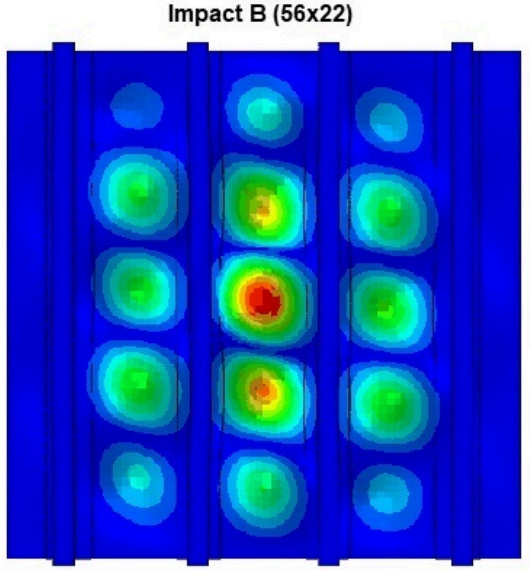

Eigenvalue: 0.10281

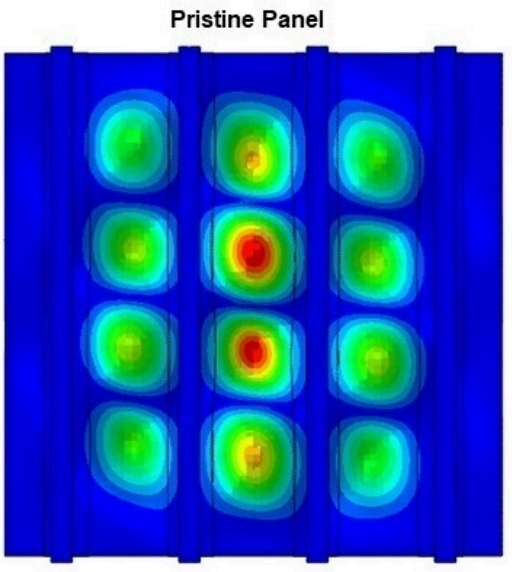

Eigenvalue: 0.10258

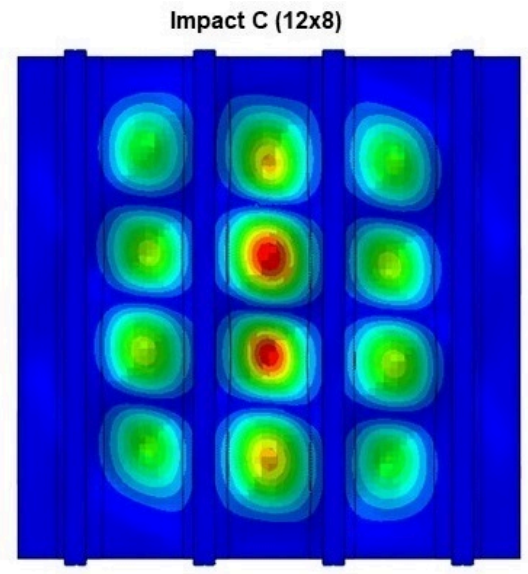

Eigenvalue: 0.10258

Figure 4: First eigenvalue/eigenmode of the pristine and impacted panels B \& C 

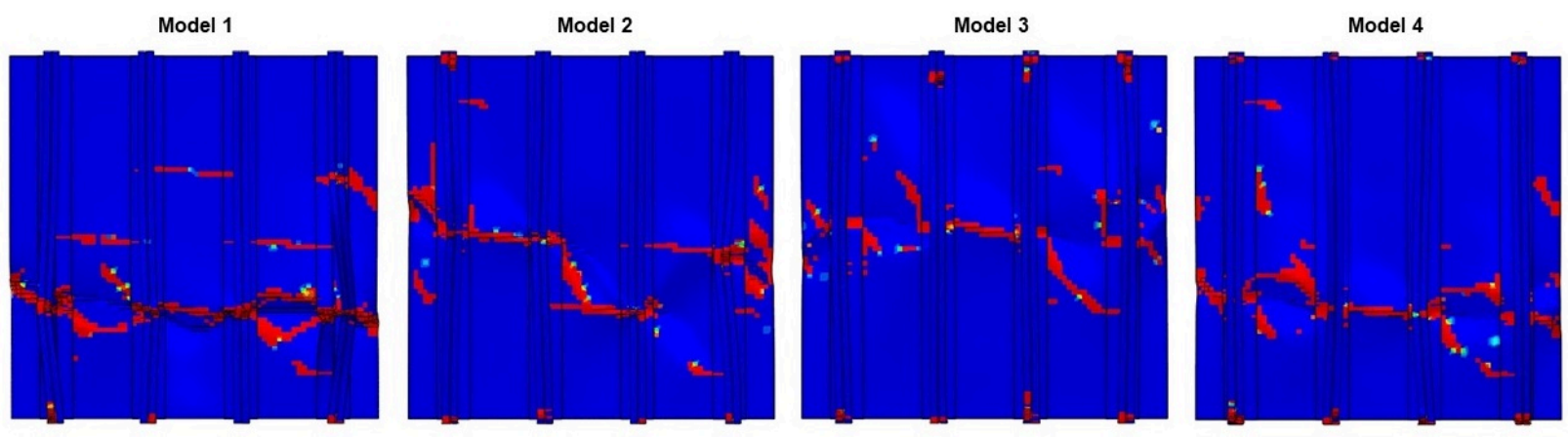

Figure 5: Matrix compression damage in the models of table 3 


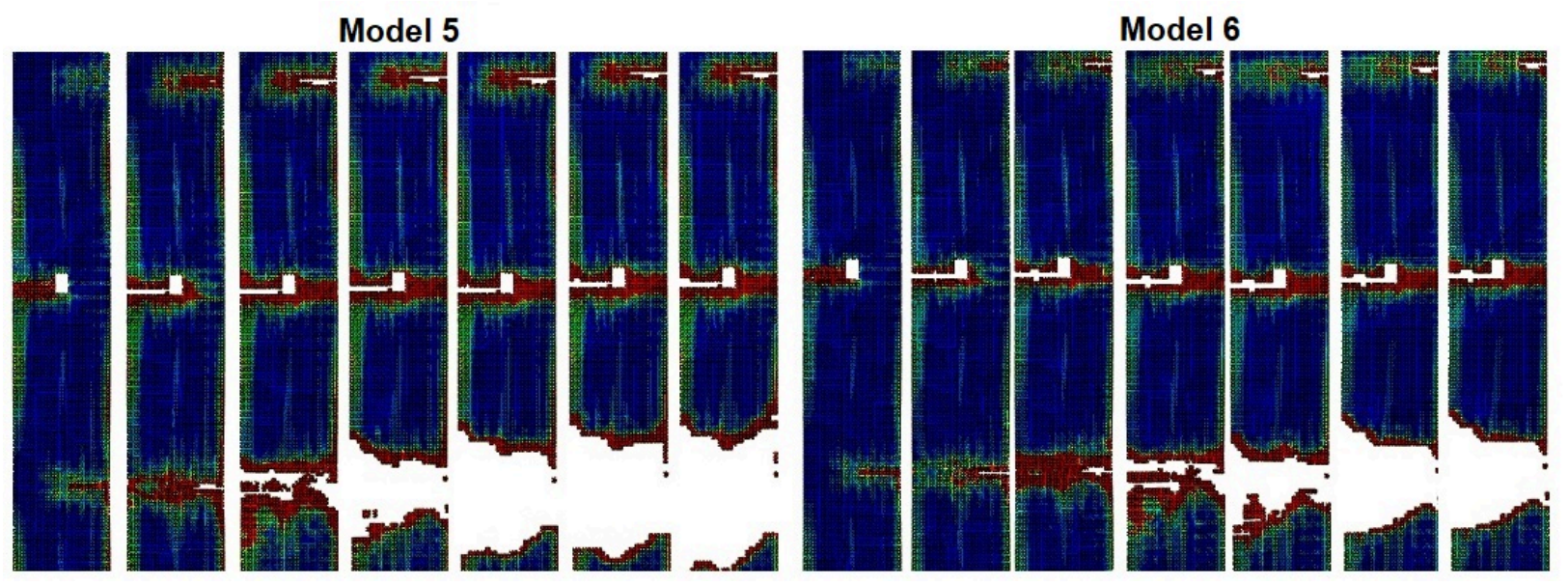

Figure 6: Quadratic nominal stress criterion in models 5 \& 6 


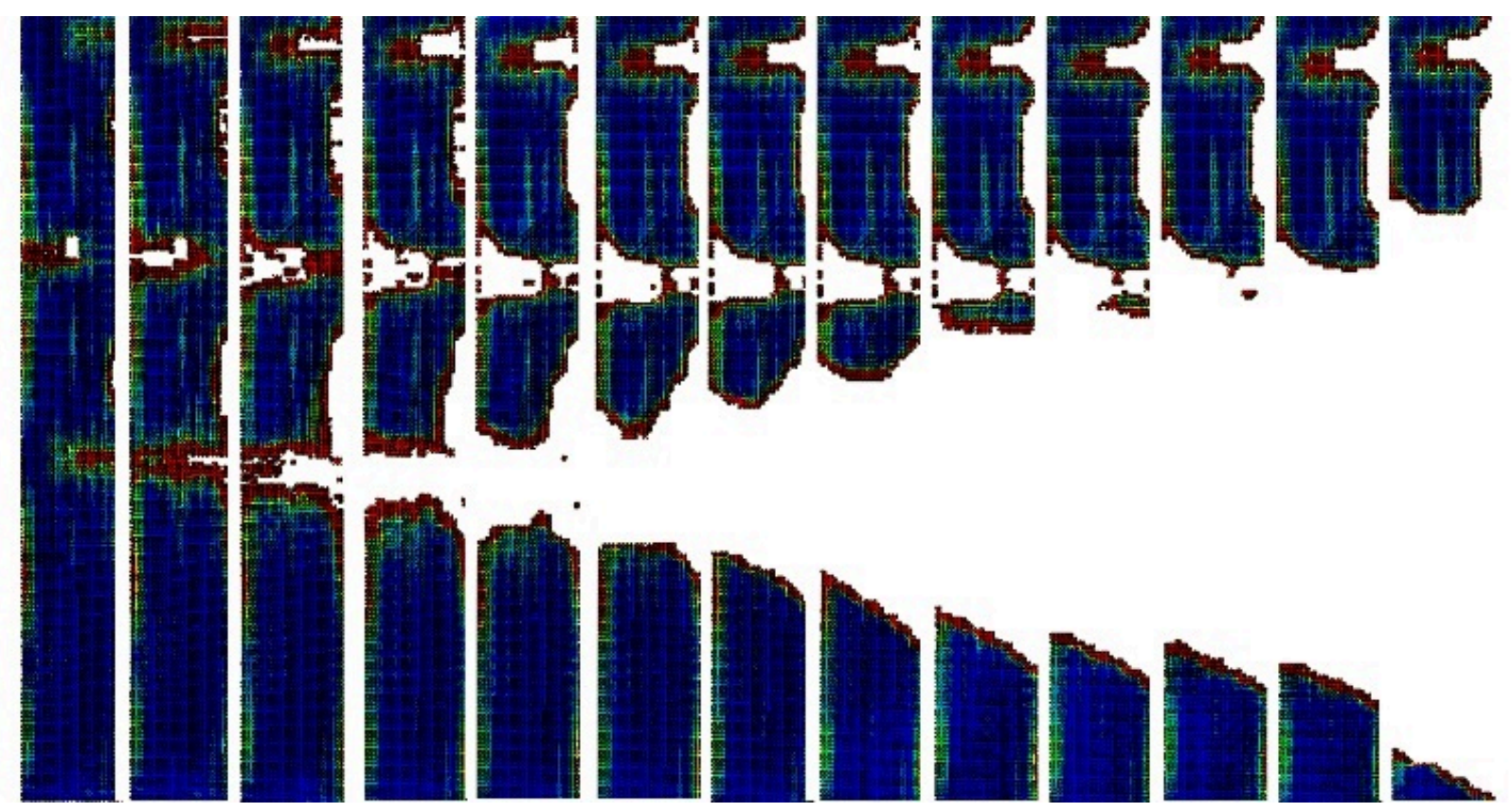

Figure 7: Quadratic nominal stress criterion in model 7 


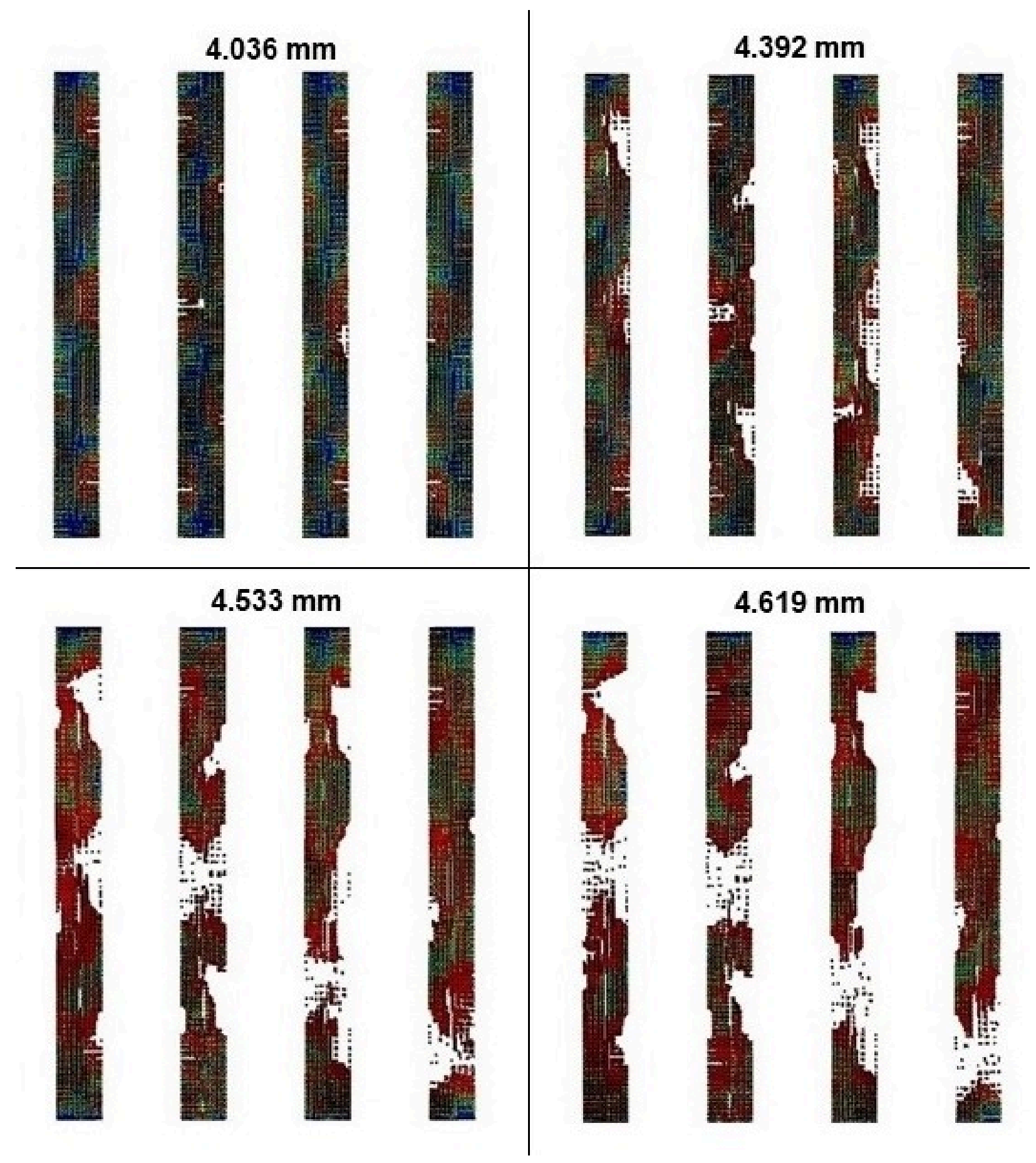

Figure 8: Quadratic nominal stress criterion in model 8 for four indicative applied displacements 
Model 3

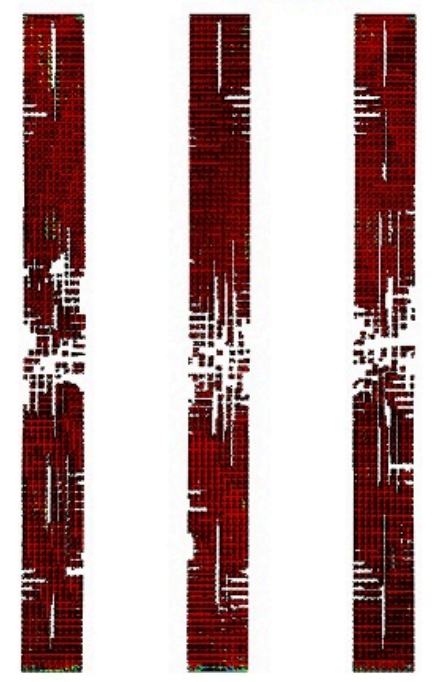

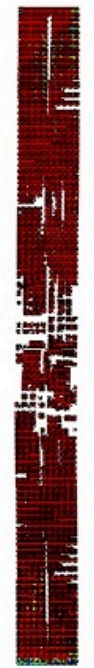

Model 4

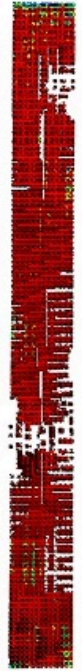

Figure 9: Quadratic nominal stress criterion in model 3 and 4 


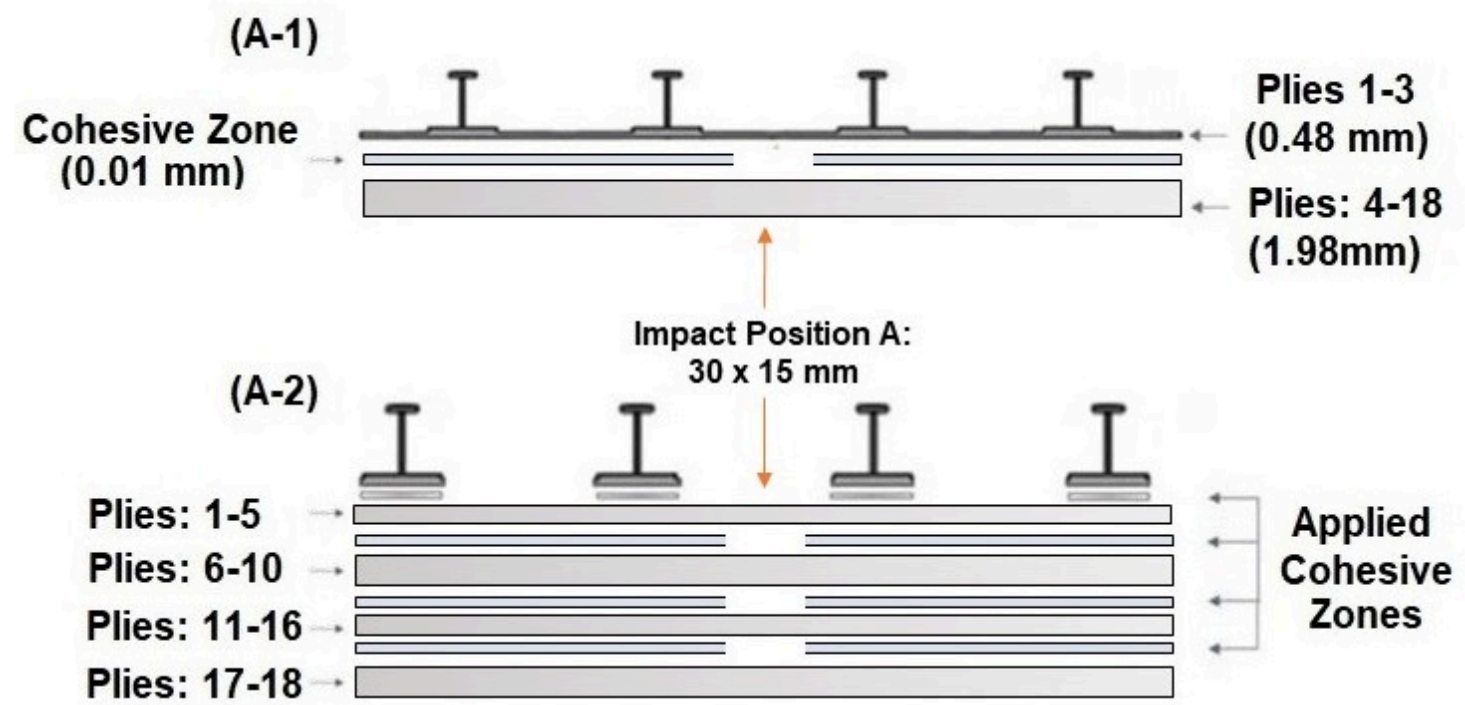

Figure 10: Schematic figure of examined impacted models in position A 

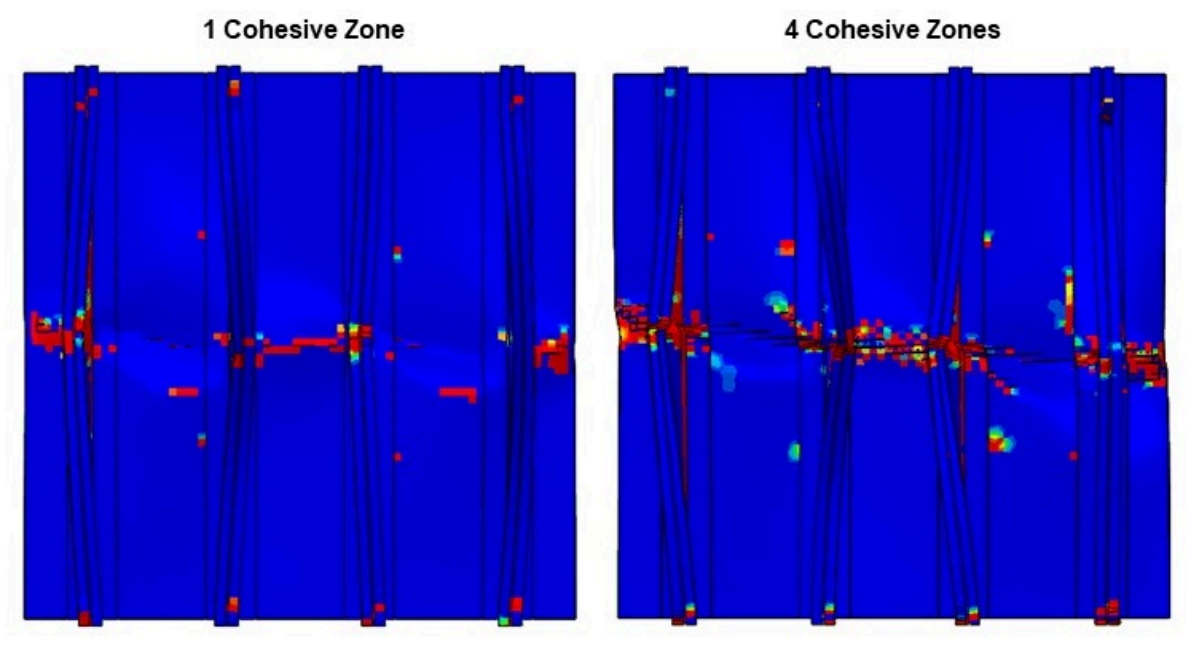

Figure 11: Tensile matrix damage in models A-1 \& A-2 
Top cohesive element

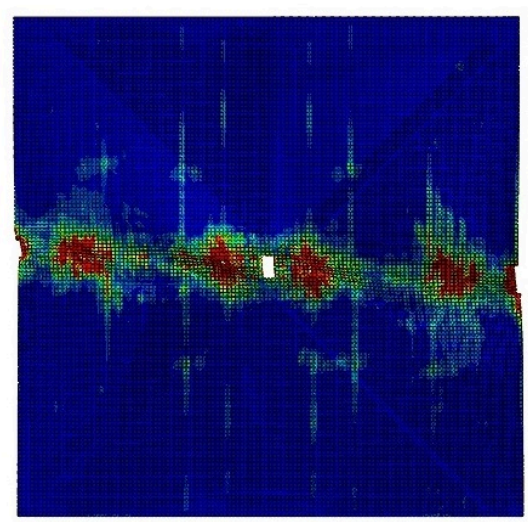

Middle cohesive element

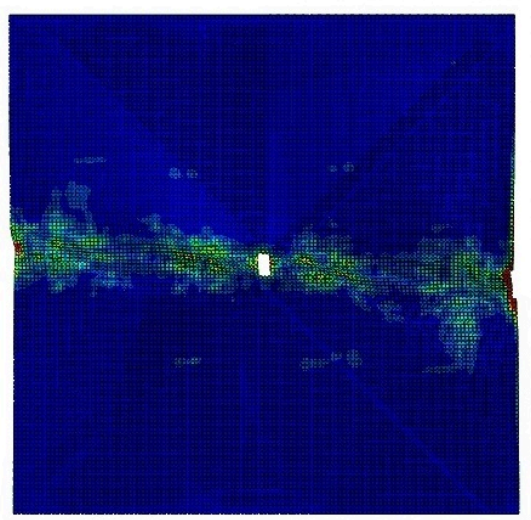

Bottom cohesive element

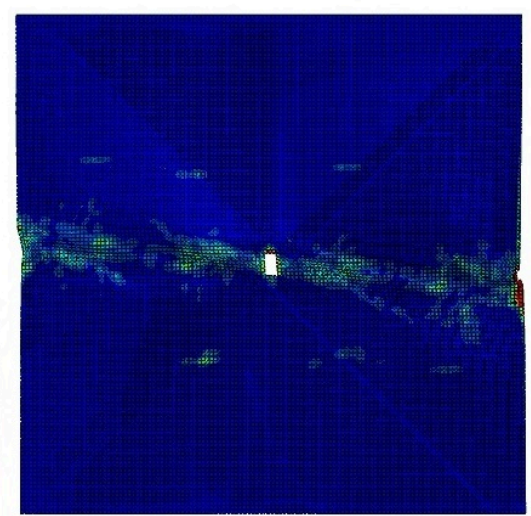

Figure 12: Quadratic nominal stress criterion within the skin in model A-2 


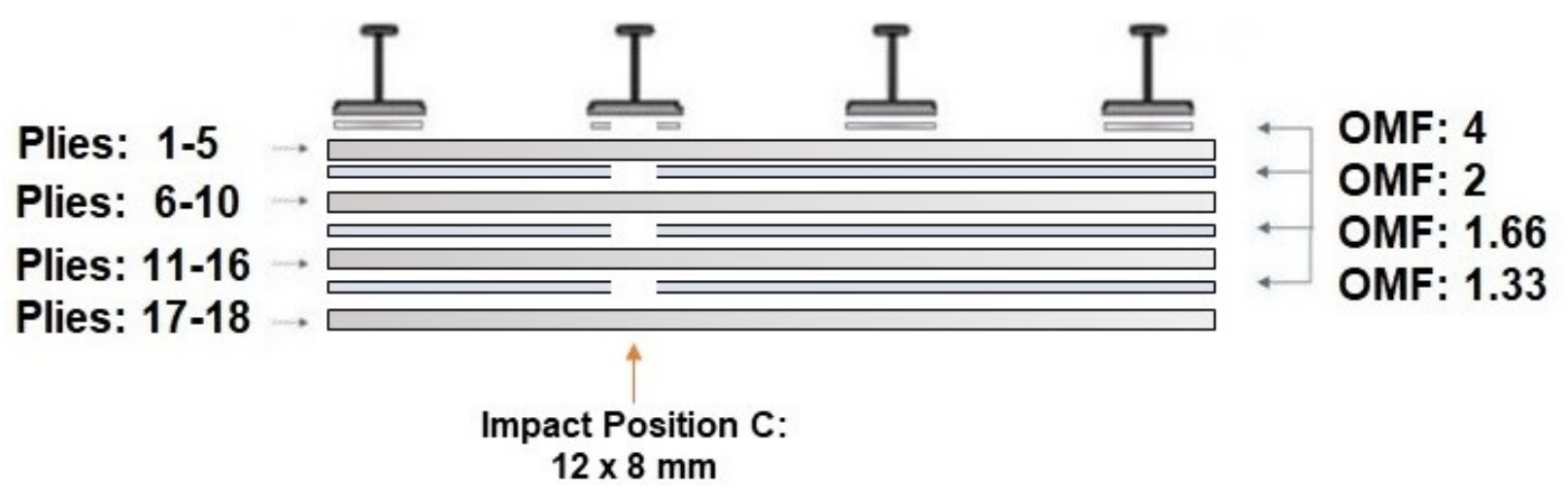

Figure 13: Schematic figure of the OMF model 
Top Cohesive Area - Damage initation

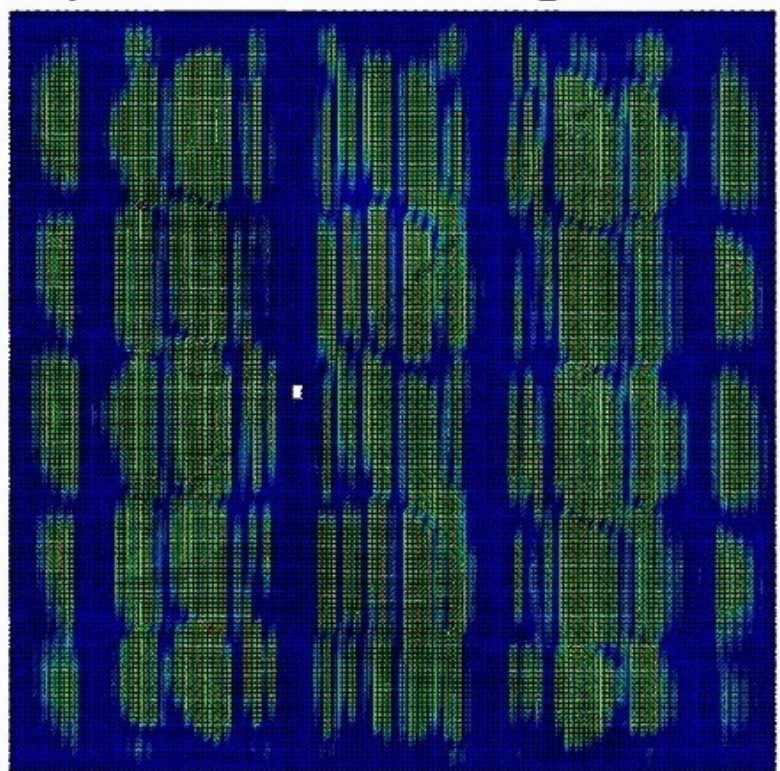

$\mathrm{OMF}=2$
Top Cohesive Area - Final Increment

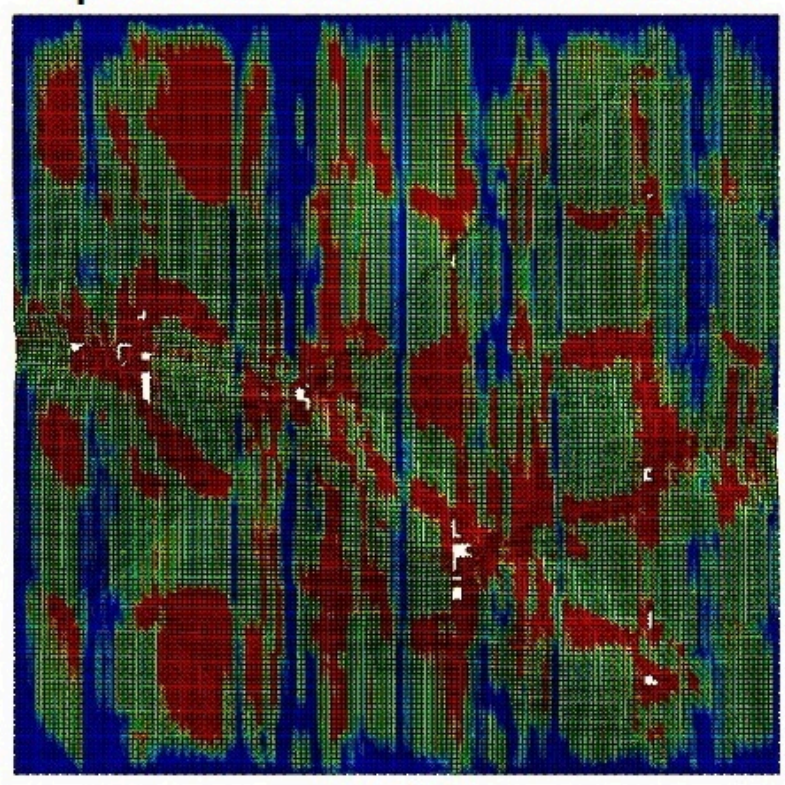

OMF $=2$

Figure 14: Quadratic nominal stress criterion with an OMF equal to 2 
Middle Cohesive Area - Final Increment

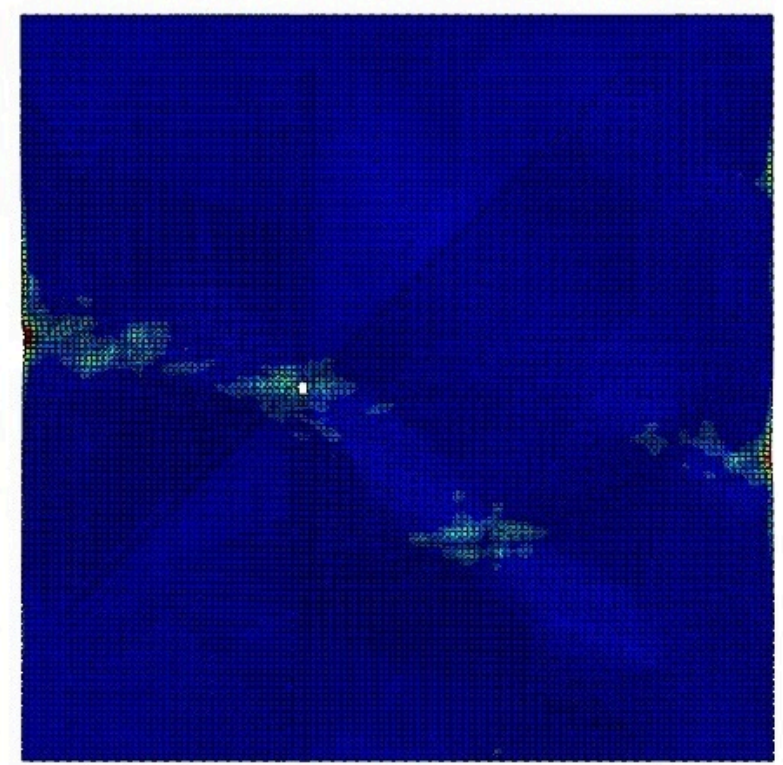

$\mathrm{OMF}=1.66$
Bottom Cohesive Area - Final Increment

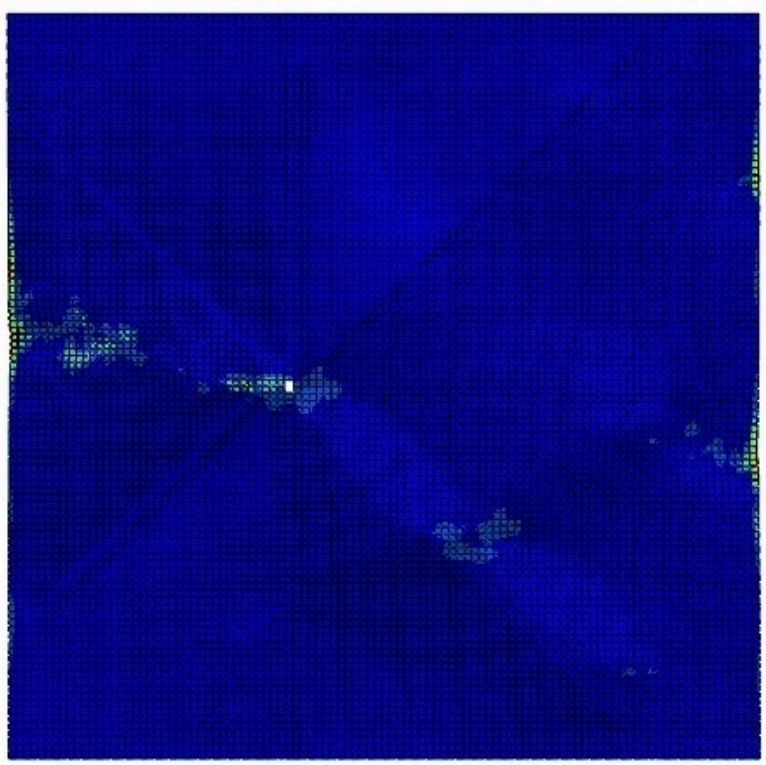

$\mathrm{OMF}=1.33$

Figure 15: Quadratic nominal stress criterion with an OMF less than 2 


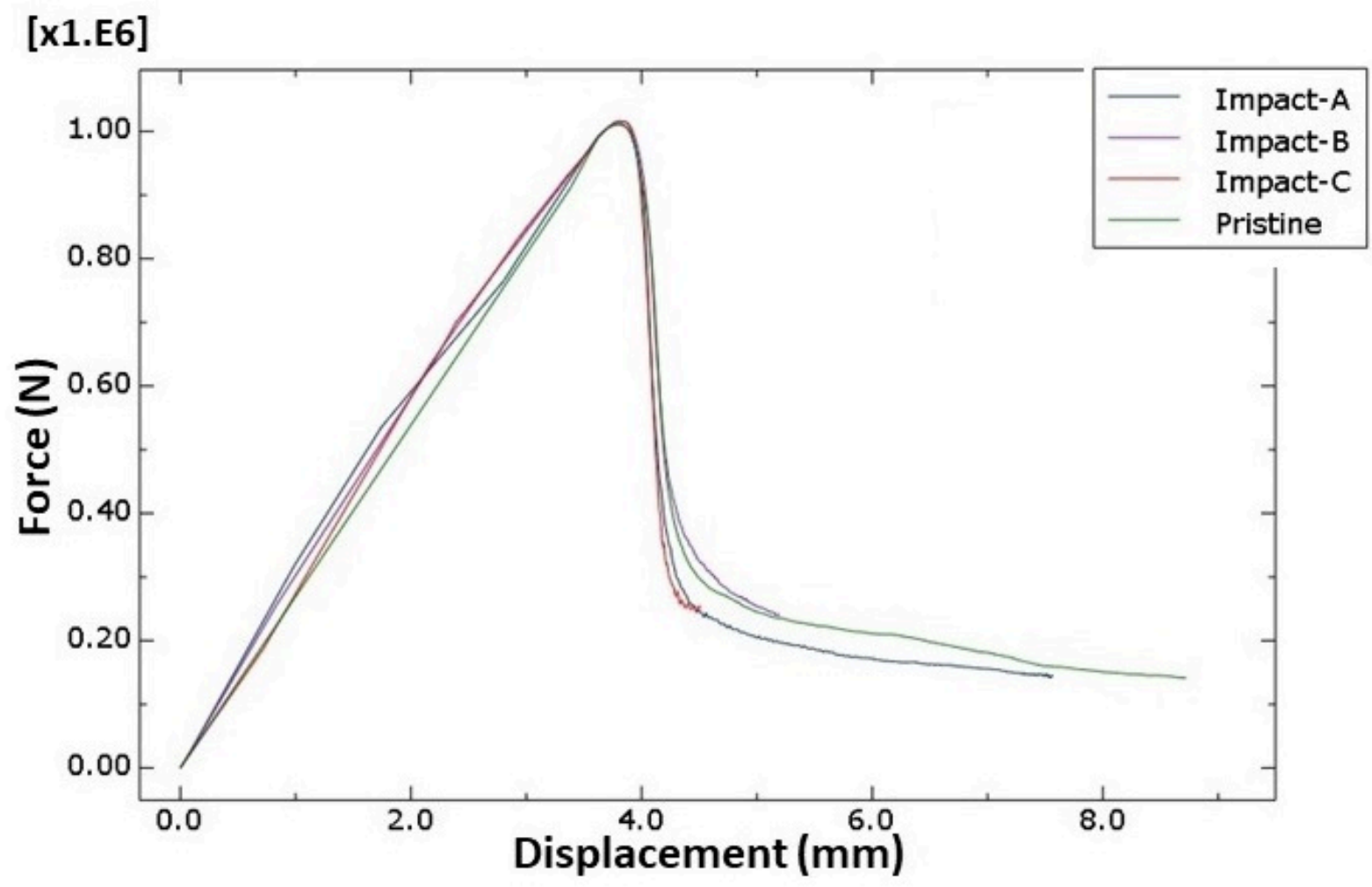

Figure 16: Force - Displacement diagrams for the pristine \& impacted panels 


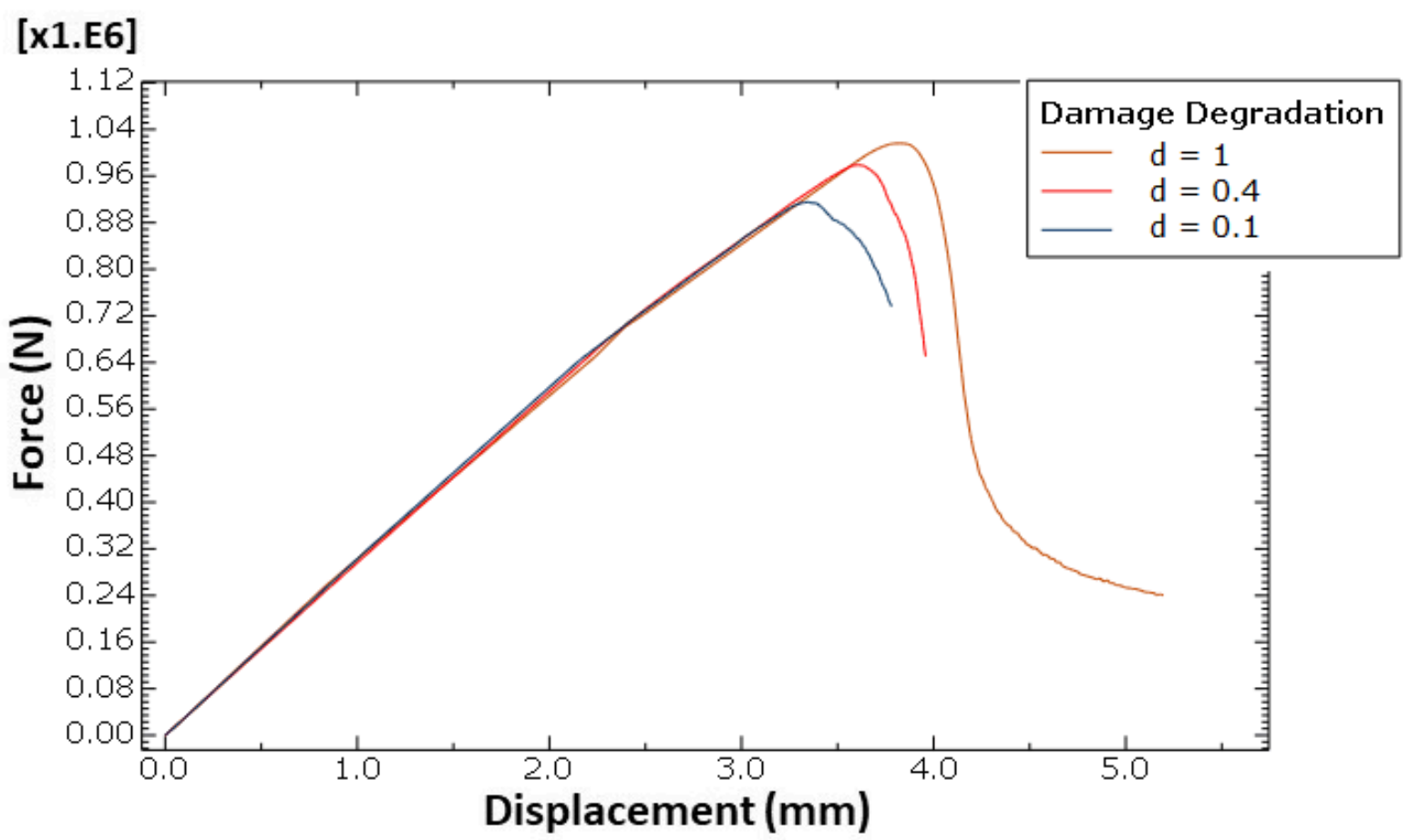

Figure 17: Force - Displacement diagrams for position B with damage degradation coefficient equal to $0.1,0.4 \& 1$ 
2019-06-10

\section{Numerical FEA parametric analysis of CAI behaviour of CFRP stiffened panels}

Gaitanelis, Dimitrios G.

Elsevier

Gaitanelis DG, Giannopoulos IK, Theotokoglou EE. (2019) Numerical FEA parametric analysis of CAI behaviour of CFRP stiffened panels. Thin-Walled Structures, Volume 143, October 2019, Article number 106231

https://doi.org/10.1016/j.tws.2019.106231

Downloaded from Cranfield Library Services E-Repository 